\title{
How to Write an Abstract?
}

Research is formalized curiosity. It is poking and prying with a purpose.

-Zora Neale Hurston, American Author, Anthropologist and Filmmaker (1891-1960)

\subsection{What is an Abstract?}

An abstract is a crisp, short, powerful, and self-contained summary of a research manuscript used to help the reader swiftly determine the paper's purpose. Although the abstract is the first paragraph of the manuscript it should be written last when all the other sections have been addressed.

An abstract is usually a standalone document that informs the reader about the details of the manuscript to follow. It is like a trailer to a movie, if the trailer is good, it stimulates the audience to watch the movie. The abstract should be written from scratch and not 'cut-and-pasted' [1].

\subsection{What is the History of the Abstract?}

An abstract, in the form of a single paragraph, was first published in the Canadian Medical Association Journal in 1960 with the idea that the readers may not have enough time to go through the whole paper, and the first abstract with a defined structure was published in 1991 [2]. The idea sold and now most original articles and reviews are required to have a structured abstract. The abstract attracts the reader to read the full manuscript [3]. 


\subsection{What are the Qualities of a Good Abstract?}

The quality of information in an abstract can be summarized by four 'C's. It should be:

- C: Condensed

- C: Clear

- C: Concise

- C: Critical

\subsection{What are the Types of Abstract?}

Before writing the abstract, you need to check with the journal website about which type of abstract it requires, with its length and style in the 'Instructions to Authors' section.

The abstract types can be divided into:

1. Descriptive: Usually written for psychology, social science, and humanities papers. It is about $50-100$ words long. No conclusions can be drawn from this abstract as it describes the major points in the paper.

2. Informative: The majority of abstracts for science-related manuscripts are informative and are surrogates for the research done. They are single paragraphs that provide the reader an overview of the research paper and are about 100-150 words in length. Conclusions can be drawn from the abstracts and in the recommendations written in the last line.

3. Critical: This type of abstract is lengthy and about 400-500 words. In this, the authors' own research is discussed for reliability, judgement, and validation. A comparison is also made with similar studies done earlier.

4. Highlighting: This is rarely used in scientific writing. The style of the abstract is to attract more readers. It is not a balanced or complete overview of the article with which it is published.

5. Structured: A structured abstract contains information under subheadings like background, aims, material and methods, results, conclusion, and recommendations (Fig. 15.1). Most leading journals now carry these.

\subsection{What is the Purpose of an Abstract?}

An abstract is written to educate the reader about the study that follows and provide an overview of the science behind it. If written well it also attracts more readers to the article. It also helps the article getting indexed. The fate of a paper both before and after publication often depends upon its abstract. Most readers decide if a paper is worth reading on the basis of the abstract. Additionally, the selection of papers in systematic reviews is often dependent upon the abstract. 


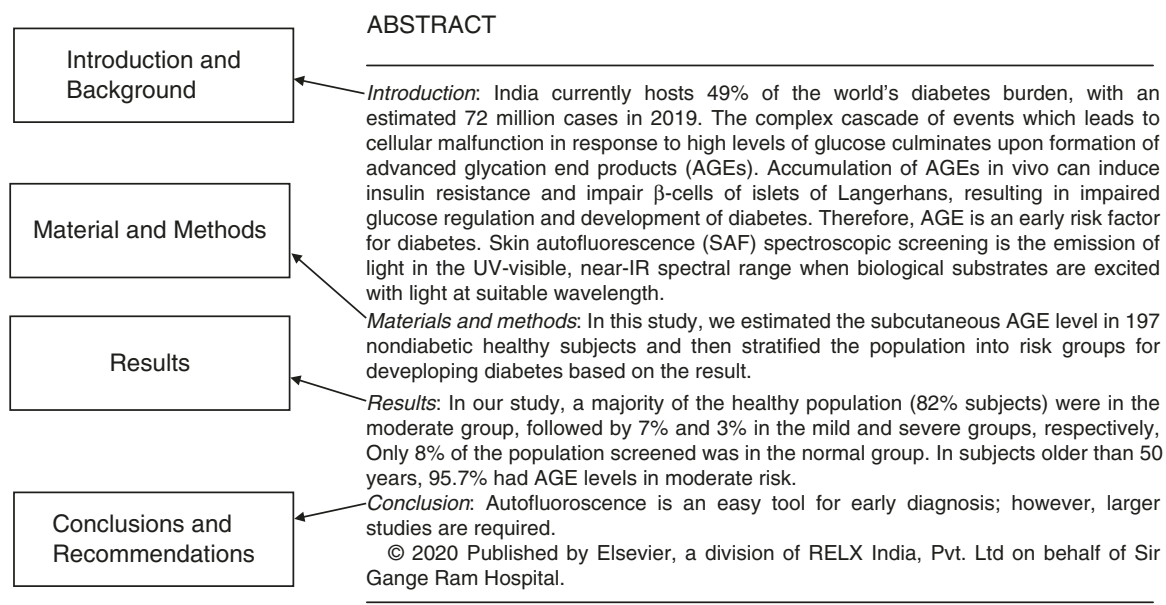

Fig. 15.1 Example of a structured abstract (with permission editor CMRP)

\subsection{What are the Steps of Writing an Abstract?}

An abstract should be written last after all the other sections of an article have been addressed. A poor abstract may turn off the reader and they may cause indexing errors as well. The abstract should state the purpose of the study, the methodology used, and summarize the results and important conclusions. It is usually written in the IMRAD format and is called a structured abstract $[4,5]$.

I: The introduction in the opening line should state the problem you are addressing.

M: Methodology_what method was chosen to finish the experiment?

R: Results-state the important findings of your study.

A: And

D: Discussion-discuss why your study is important.

Mention the following information:

- Important results with the statistical information ( $p$ values, confidence intervals, standard/mean deviation).

- Arrange all information in a chronological order.

- Do not repeat any information.

- The last line should state the recommendations from your study.

- The abstract should be written in the past tense. 


\subsection{What are the Things to Be Avoided While Writing an Abstract?}

\subsubsection{Do Not}

- Cut and paste information from the main text

- Hold back important information

- Use abbreviations

- or include

- Tables or Figures

- Quotations

- Generalized statements

- References

- Arguments about the study

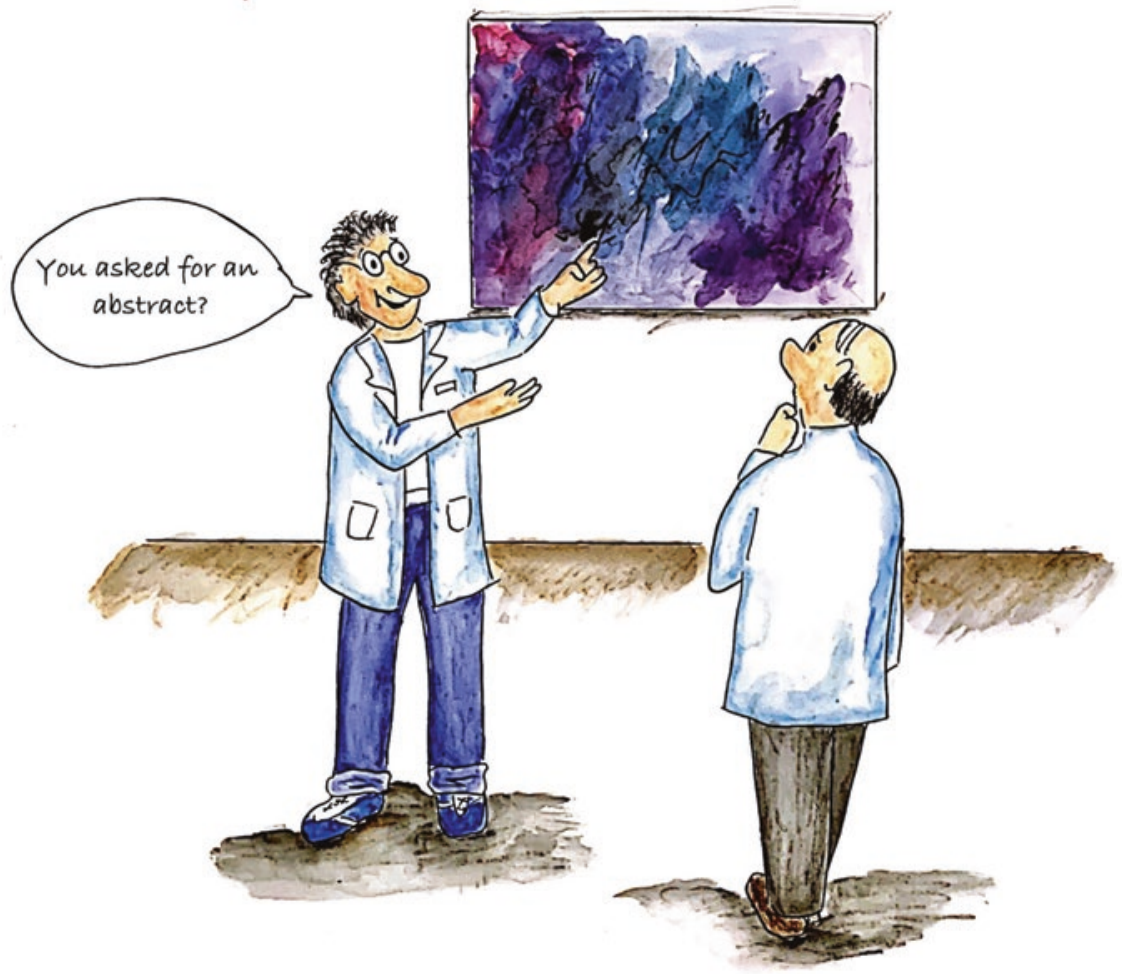




\subsection{What are Key Words?}

These are important words that are repeated throughout the manuscript and which help in the indexing of a paper. Depending upon the journal 3-10 key words may be required which are indexed with the help of MESH (Medical Subject Heading).

\subsection{How is an Abstract Written for a Conference Different from a Journal Paper?}

The basic concept for writing abstracts is the same. However, in a conference abstract occasionally a table or figure is allowed. A word limit is important in both of them. Many of the abstracts which are presented in conferences are never published in fact one study found that only $27 \%$ of the abstracts presented in conferences were published in the next five years [6].

Table 15.1 gives a template for writing an abstract.

\subsection{What are the Important Recommendations of the International Committees of Medical Journal of Editors?}

The recommendations are [7]:

- An abstract is required for original articles, metanalysis, and systematic reviews.

- A structured abstract is preferred.

Table 15.1 Content of the abstract writing

\begin{tabular}{l|l}
\hline Section & Details \\
\hline Background & $\begin{array}{l}\text { 1-2 lines of background material to focus the significance of the study } \\
\text { query/hypothesis: } \\
\text { - What is the known data? } \\
\text { - What is the knowledge gap? }\end{array}$ \\
\hline $\begin{array}{l}\text { Study postulate } \\
\text { details }\end{array}$ & $\begin{array}{l}\text { What the study was planned to discover? } \\
\text { blinding, placebo control, criterion standards for diagnostic tests }\end{array}$ \\
\hline & $\begin{array}{l}\text { Setting: Outpatient department, hospitalized patient, community-based } \\
\text { data }\end{array}$ \\
\hline $\begin{array}{l}\text { Materials/subjects/participants: } \\
\text { - The resources studied } \\
\text { - The details of participants (number, sex) } \\
\text { - Intection criteria-inclusion and exclusion } \\
\text { - Outcome of interest }\end{array}$ \\
\hline $\begin{array}{l}\text { Results } \\
\text { findings }\end{array}$ & $\begin{array}{l}\text { A sentence the most important results that answer the research question } \\
\text { speculations based on the answer }\end{array}$ \\
\hline
\end{tabular}


- The abstract should mention the purpose of the scientific study, how the procedure was carried out, the analysis used, and principal conclusion.

- Clinical trials should be reported according to the CONSORT guidelines.

- The trials should also mention the funding and the trial number.

- The abstract should be accurate as many readers have access only to the abstract.

\subsection{Conclusions}

- An Abstract should be written last after all the other sections of the manuscript have been completed and with due care and attention to the details.

- It should be structured and written in the IMRAD format.

- For many readers, the abstract attracts them to go through the complete content of the article.

- The abstract is usually followed by key words that help to index the paper.

\section{References}

1. Andrade C. How to write a good abstract for a scientific paper or conference presentation? Indian J Psychiatry. 2011;53:172-5.

2. Squires BP. Structured abstracts of original research and review articles. CMAJ. 1990;143:619-22.

3. Pierson DJ. How to write an abstract that will be accepted for presentation at a national meeting. Respir Care. 2004 Oct;49:1206-12.

4. Tenenbein M. The abstract and the academic clinician. Pediatr Emerg Care. 1995;11:40-2.

5. Bahadoran Z, Mirmiran P, Kashfi K, Ghasemi A. The principles of biomedical scientific writing: abstract and keywords. Int J Endocrinol Metab. 2020;18:e100159.

6. Grover S, Dalton N. Abstract to publication rate: do all the papers presented in conferences see the light of being a full publication? Indian J Psychiatry. 2020;62:73-9.

7. Preparing a manuscript for submission to a medical journal. Available on http://www.icmje.org/ recommendations/browse/manuscript-preparation/preparing-for-submission.html. Accessed 10 May 2020.

Open Access This chapter is licensed under the terms of the Creative Commons Attribution 4.0 International License (http://creativecommons.org/licenses/by/4.0/), which permits use, sharing, adaptation, distribution and reproduction in any medium or format, as long as you give appropriate credit to the original author(s) and the source, provide a link to the Creative Commons license and indicate if changes were made.

The images or other third party material in this chapter are included in the chapter's Creative Commons license, unless indicated otherwise in a credit line to the material. If material is not included in the chapter's Creative Commons license and your intended use is not permitted by statutory regulation or exceeds the permitted use, you will need to obtain permission directly from the copyright holder.

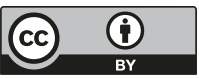

